\title{
Understanding How Students Study: The Genealogy and Conceptual Basis of A Widely Used Pedagogical Research Tool, Biggs' Study Process Questionnaire
}

\author{
Warren Lake ${ }^{1}$, William Boyd ${ }^{1} \&$ Wendy Boyd ${ }^{2}$ \\ ${ }^{1}$ School of Environment, Science \& Engineering, Southern Cross University, Lismore, Australia \\ ${ }^{2}$ School of Education, Southern Cross University, Lismore, Australia \\ Correspondence: Warren Lake, School of Environment, Science \& Engineering, Southern Cross University, \\ Lismore, Australia Tel: 61-415-199-523. E-mail: warren.lake@scu.edu.au
}

\author{
Received: November 23, $2016 \quad$ Accepted: December 30, $2016 \quad$ Online Published: April 29, 2017 \\ doi:10.5539/ies.v10n5p100 URL: https://doi.org/10.5539/ies.v10n5p100
}

\begin{abstract}
The Study Process Questionnaire (SPQ) continues to be applied in a wide range of pedagogical situations. However, the question remains as to how well a researcher understands the conceptual basis behind the tool they choose. This essay provides a compact and comprehensive view of the conceptual basis for the development of the original SPQ, and the later revised version (R-SPQ-2F), and offers a way for a researcher to quickly be informed on the concepts underpinning the tool, enabling the opportunity to quickly assess whether the R-SPQ-2F is an appropriate tool to be using in there study. In this essay we look at the earliest stages in the development of the SPQ, through to the development of the revised Study Process Questionnaire unpacking the underlying conceptual model.
\end{abstract}

Keywords: Biggs, study process questionnaire, SPQ, revised study process questionnaire, R-SPQ-2F, P3 model

\section{Introduction}

The Revised Study Process Questionnaire (R-SPQ-2F) (Biggs, Kember, \& Leung, 2001) continues to be applied in higher education research across a range of different subject areas (Stes, De Maeyer, \& Van Petegem, 2013). The Questionnaire is based on a series of conceptual developments starting from as early as the 1920s with studies regarding study habits, through to the 1970s where scholars started to understand that good study behaviour cannot simply be applied broadly to students. From this body of knowledge, the original Study Process Questionnaire (SPQ) was born (Biggs, 1987) and continued to be refined in the form of the revised version, which is still used in the assessment of student learning approaches in a variety of pedagogical contexts (Stes et al., 2013).

Although some researchers consider the SPQ to be obsolete, there is ongoing popularity of the tool particularly the revised two-factor study process questionnaire (R-SPQ-2F) (Biggs et al., 2001). To demonstrate this point, the R-SPQ-2F has been cited 328 times according to Web of Science forward citation mapping Java platform and 352 times in the Web of Science core collection. The continued importance of the Biggs et al. 2001 study is highlighted as it has been cited in at least 56 publications since 2015 (Figure 1). The ongoing implementation of the tool directly highlights the need for researchers to have easy access to the conceptual and practical development of the survey. This essay presents in chronological order the series of studies that led to the development of the R-SPQ-2F and the conceptual model which underlies it. 


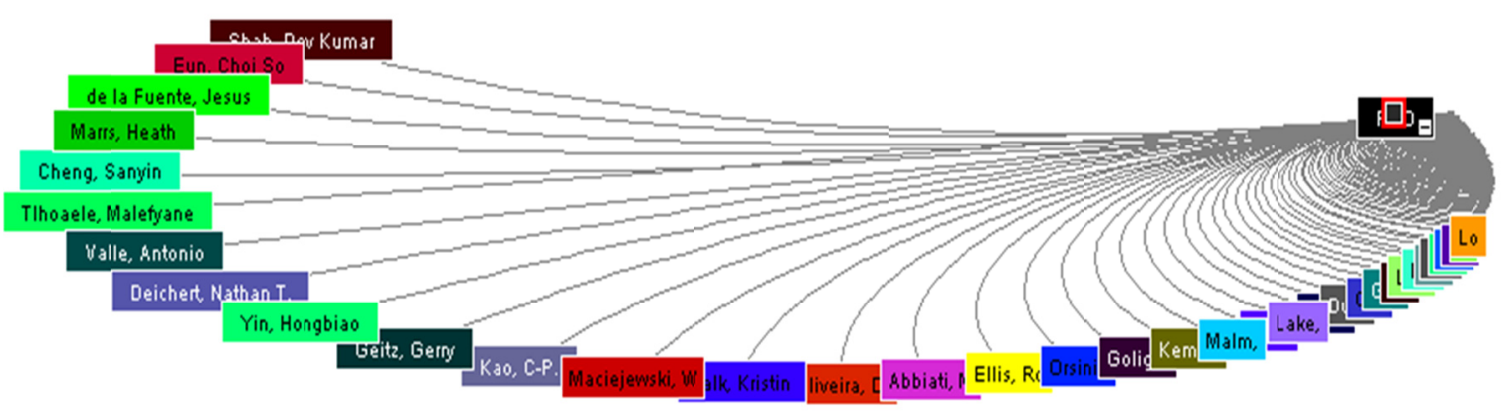

Figure 1. Sample of results 2016 and 2015 from the Web of Science forward citation map

\section{Study Behavior-Early Development}

Between 1926 and 1955, more than one hundred books and manuals relating to study habits and attitudes were produced in America, highlighting the importance educators placed on the role of study in learning and academic success (Brown \& Holtzman, 1955). However, these books and manuals lacked pertinent academic support (Brown \& Holtzman, 1955). One of the first study habit inventories was published by Wrenn in 1933 (revised in 1941) (Brown \& Holtzman, 1955; Wrenn, 1941), and was developed to "... measure factors that contribute to good academic achievement" (Sherman, 1991, p. 89). This publication was followed up with sound empirical investigations which showed a weak relationship between scores on the inventory and student success (Brown \& Holtzman, 1955). These studies in to 'study processes' focused on the idea that study methods relate independently to academic performance in university education (Biggs, 1978).

Although the relationship between study methods and performance could be shown in some cases, the variance accounted for, was generally relatively small (Entwistle \& Wilson, 1977, cited in Biggs, 1978). Assumptions of many scholars prior to 1970 , included the idea that study behaviour related directly to the students' performance in examinations (Biggs, 1970). However, results of various studies related to the most common research tool into study behaviour in the 1950s and 60s, the Survey of Study Habits and Attitudes (SSHA), showed that in many cases students checking good study habits were frequently found to perform better than those checking poor habits (e.g. Brown \& Holtzman, 1955; Carter, 1948) (Biggs, 1970). In contradiction, other studies (e.g. Ahmann \& Glock, 1957; Cooper \& Foy, 1969; Gibbons \& Savage 1965; Shatin 1969), have shown a null relationship, which was also confirmed in studies with Australian students (Biggs, 1970).

\section{The 70s and the Presage-Process-Product Paradigm}

This led Biggs (1970) to the view that good study behaviour cannot simply be applied broadly to students and courses (Biggs, 1970). Interestingly, Biggs (1970) cites a study by Lafitte (1963) where it was established that some of the best performing students had some of the least desirable study skills, instead noting the fact that high performing students were more efficient, not wasting time on unprofitable activities. Clearly later models related to the student learning and the 'study process complex' draw on this early understanding regarding the complexities of student learning and study behaviours (e.g. Biggs, 1976).

By the mid-1970s, Biggs recognised that research into the identification of the one best method of studying had ended (Biggs, 1976). This understanding, as well as clear evidence that successful students do not necessarily follow the same path to success (Entwistle, Nisbet, Entwistle, \& Cowell, 1971), led Biggs (1978) to propose a more complex model that included a complex of tactics, strategies and approaches moderating between determining factors and academic performance (Figure 2). This description was supplemented by a more comprehensive version of this model, referred to as a 'general model of study processes', which highlighted a presage-process-product paradigm (also referred to as the 3P model) (see Figure 3). Basing this idea on a Lewinian model, (that is behaviour as an interactive function of person and environment), Biggs (1978) stated that "Study processes are postulated to intervene between classes of presage variables (personological, institutional) and product variables (academic performance)." (p. 266). In addition, this basic model was described as having been based on Dunkin and Biddle's (1974) model related to classroom teaching of student learning (Biggs, 1993a).

The more modern example of this model was illustrated in Biggs (1993a) (see Figure 4). This model describes a linear progression from presage to process to product (as was the case with earlier models), but highlights the 
idea that each component interacts with all other components as an integrated system (Biggs, 1993a) and consists of a variety of feedback components (including metacognition components).

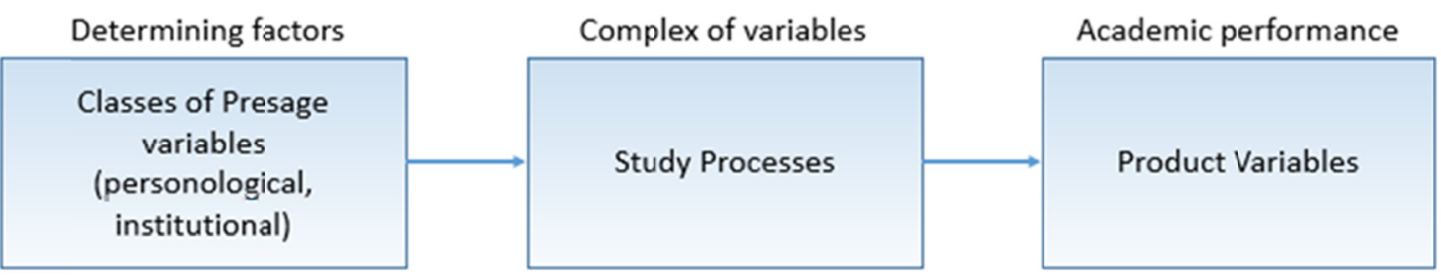

Figure 2. Basic descriptive model indicating the relationships between presage variables, study processes, and product variables (Biggs, 1978)

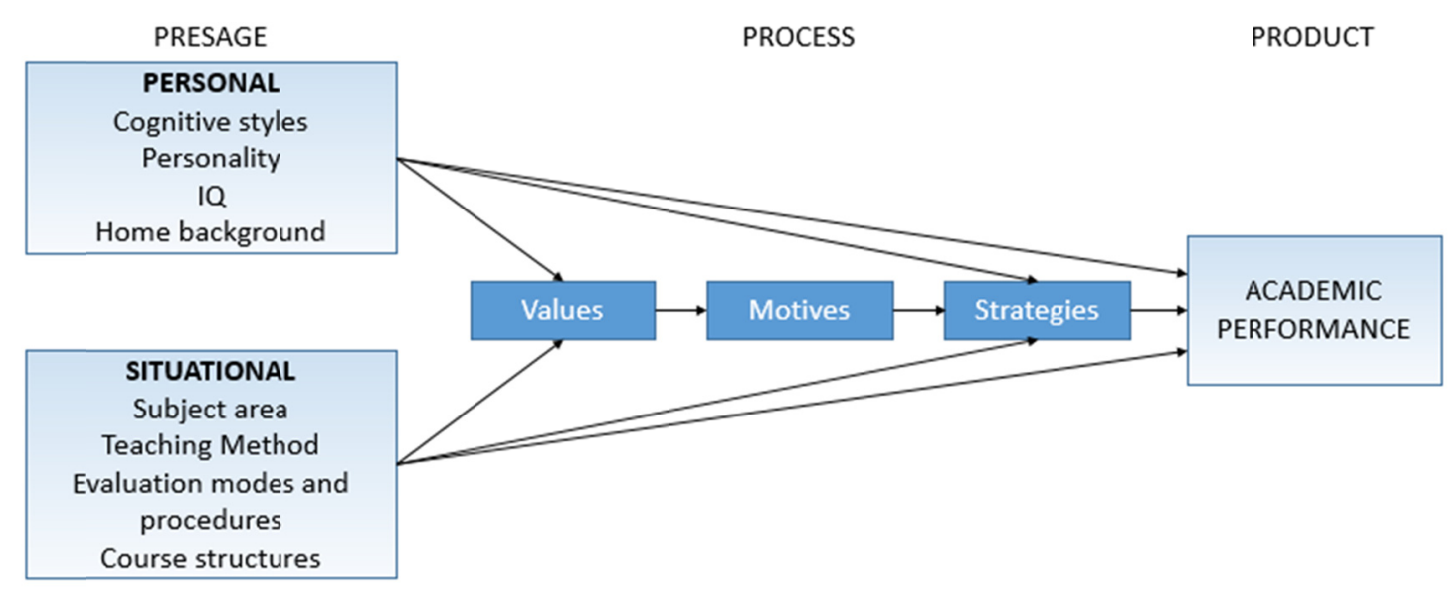

Figure 3. General model of study processes illustrating a presage-process-product paradigm (Biggs, 1978)

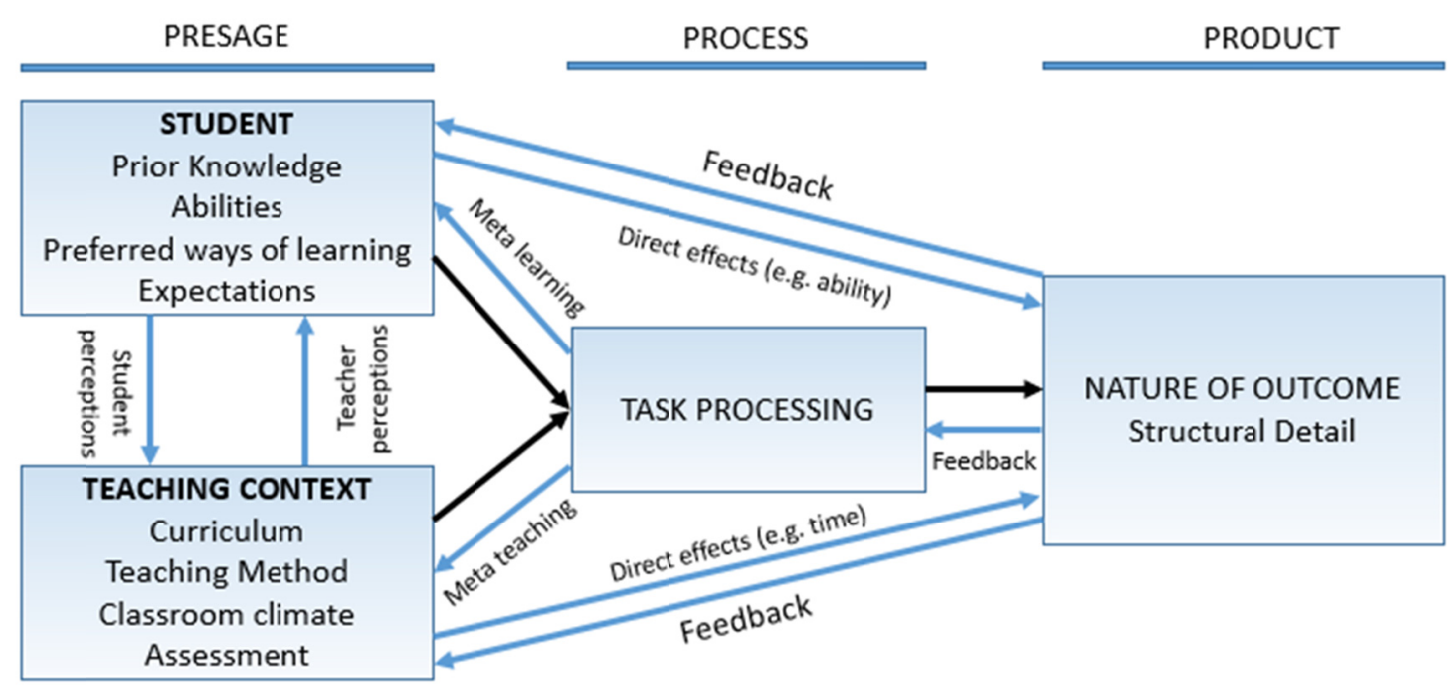

Figure 4. P3 model of classroom learning (dark arrows represent the main thrust of the model) (Biggs, 1993a)

\section{Initial Development of the Original SPQ based on the P3 Model}

The first reference in literature to the Study Process Questionnaire (SPQ) appears in Biggs (1978) and includes an analysis of previously identified dimensions of study processes (see Table 1). The questions used in Biggs 
(1976) were based on study behaviour items established in earlier studies (e.g. Biggs, 1970; 1973). These items, of which there were 102, were defined into roughly ten items per dimension with 22 items not meeting the requirement of an R value (+0.3) (Biggs, 1976). Thus, the Study Behaviour Questionnaire (SBQ) referred to in Biggs (1976) consisted of a set of 80 items, based on underlying Information Processing theory (Biggs, 1993a). A major issue with the SBQ was that it had too many scales to be useful, with practitioners finding difficulty determining which scales were most relevant to their teaching practice (Biggs, 1993a).

The items Biggs analysed (1978) showed that a stable second-order structure consisting of three orthogonal (statistically independent) dimensions could be identified: namely; Reproducing, Internalising and Organising (see Figure 5). These three orthogonal dimensions were described as being part of a model that considers students as having the potential to make use of mixed motives and multiple strategies (Biggs, 1979). These were then aptly referred to as higher order factors in a Study Process Questionnaire (SPQ) in a subsequent publication (e.g. Biggs, 1979). This second order structure remained complementary to the presage-process-product model, while remaining in line with theoretical developments (Biggs, 1993a). Subsequently, items were correlated with these higher order factors (Biggs, 1979) and fell into two groups (affective and cognitive) forming congruent motive-strategy combinations (Biggs, 1993a). Thus, the first appearance of the motive-strategy congruence theory arose after the three main scales were recognised in Biggs (1978) and the analysis of items in Biggs (1979). The motive-strategy congruence theory was further applied in the final version of the original SPQ (Biggs, 1987) and further supported by Watkins and Hattie (1992) where it was found that students tended to utilize learning strategies congruent with their motivation for learning. An example of a pair of motive-strategy questions can be illustrated in the most recent revision of the SPQ (R-SPQ-2F) (see Biggs et al., 2001). For example question one in the R-SPQ-2F survey asks the student to respond to a motive type question "I find that at times studying gives me a feeling of deep personal satisfaction". This is supported by a congruent-strategy based question which asks the student to respond to the following question "I find that I have to do enough work on a topic so that I can form my own conclusions before I am satisfied".

The P3 model is based on the idea that presage factors are present before engagement in learning takes place, and can be one of two types: Students presage factors and Teaching presage factors; that interact (Biggs, 1993a). This interaction includes;

1) The teacher's perception of student motives and abilities that influence teaching decisions.

2) The student perception of the teaching context and how that affects their motives, predispositions, and decisions for action (Biggs, 1993a).

First signs of the modern nomenclature (deep, surface, and achieving approach) take their roots in Biggs (1979), where Biggs relates the second order structures (internalising, and utilising) to Marton and Saljo's (1976) surface and deep level processing terminology. Biggs eventually renames internalising and utilising approaches to surface, deep, and achieving approaches, aligning them to usage by other authors (Biggs, 1985).

Table 1. The 10 "unidimensional" dimensions, as defined by Biggs (1978)

\begin{tabular}{lcc}
\hline Dimensions in Biggs (1978) & Number of items & Description \\
\hline Pragmatism & 10 & Grade oriented; university as a means to an end. \\
\hline Academic motivation & 10 & Intrinsically motivated. \\
\hline Academic neuroticism & 7 & Overwhelmed/confused by demands of course. \\
\hline Internality & 8 & Uses internal, self-determined standards of truth. \\
\hline Study skills & 8 & Works consistently, reviews, and schedules work. \\
\hline Rote Learning & 8 & Focused on facts/details and rote learns them. \\
\hline Meaningful learning & 6 & Reads widely /relates information to what is known. \\
\hline Test anxiety & 6 & Fear of failure. \\
\hline Openness & 8 & Sees university as a place where values are investigated. \\
\hline Class dependence & 7 & Needs class structure and rarely asks questions. \\
\hline
\end{tabular}




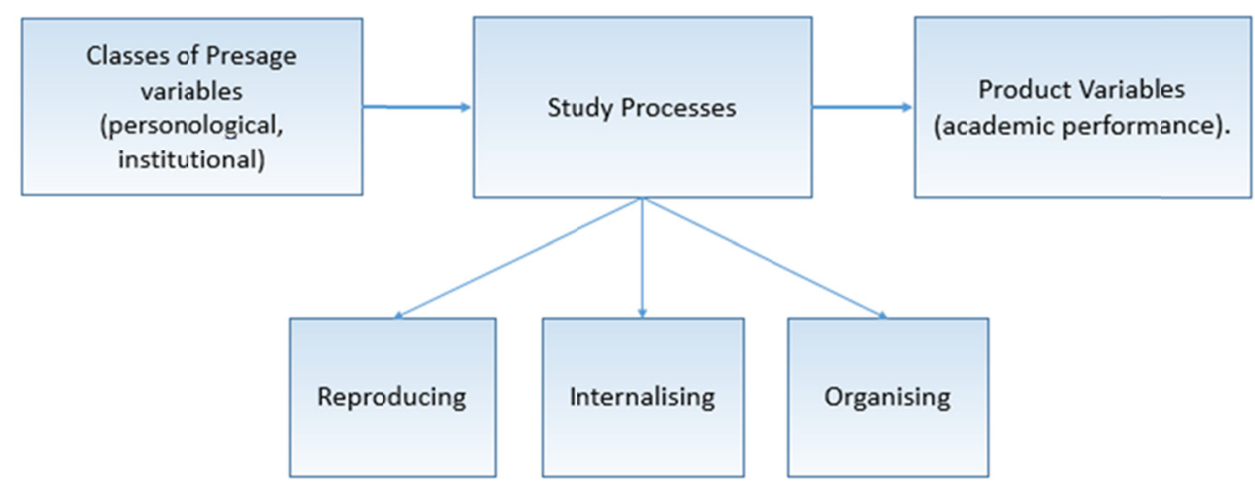

Figure 5. Basic model showing the relationship between a general learning and a second-order structure consisting of three orthogonal (statistically independent) dimensions (adapted from Biggs, 1978)

Importantly, Biggs (1979) makes it clear that “...while the SPQ dimensions may not exhaustively map the study process domain, they do seem to offer a parsimonious and theoretically coherent model for conceptualising the more important ways in which students may feel about, and behave towards, their study" (p. 383).

The main thrust of the P3 model remains in subsequent publications related to the SPQ (e.g. Biggs, 1987), however, the focus is turned to the approach to learning, using the scale previously established (deep, surface, and achieving) and to the motive-strategy complex related to each of these main scales (see Figure 6). Interestingly, the presage factors (personal and situational) are not depicted as having direct impacts on academic performance, as was the case in earlier examples (see Figure 3), but for the sake of the questionnaire are depicted to operate (apart from tactics) exclusively through the process component of the P3 model.

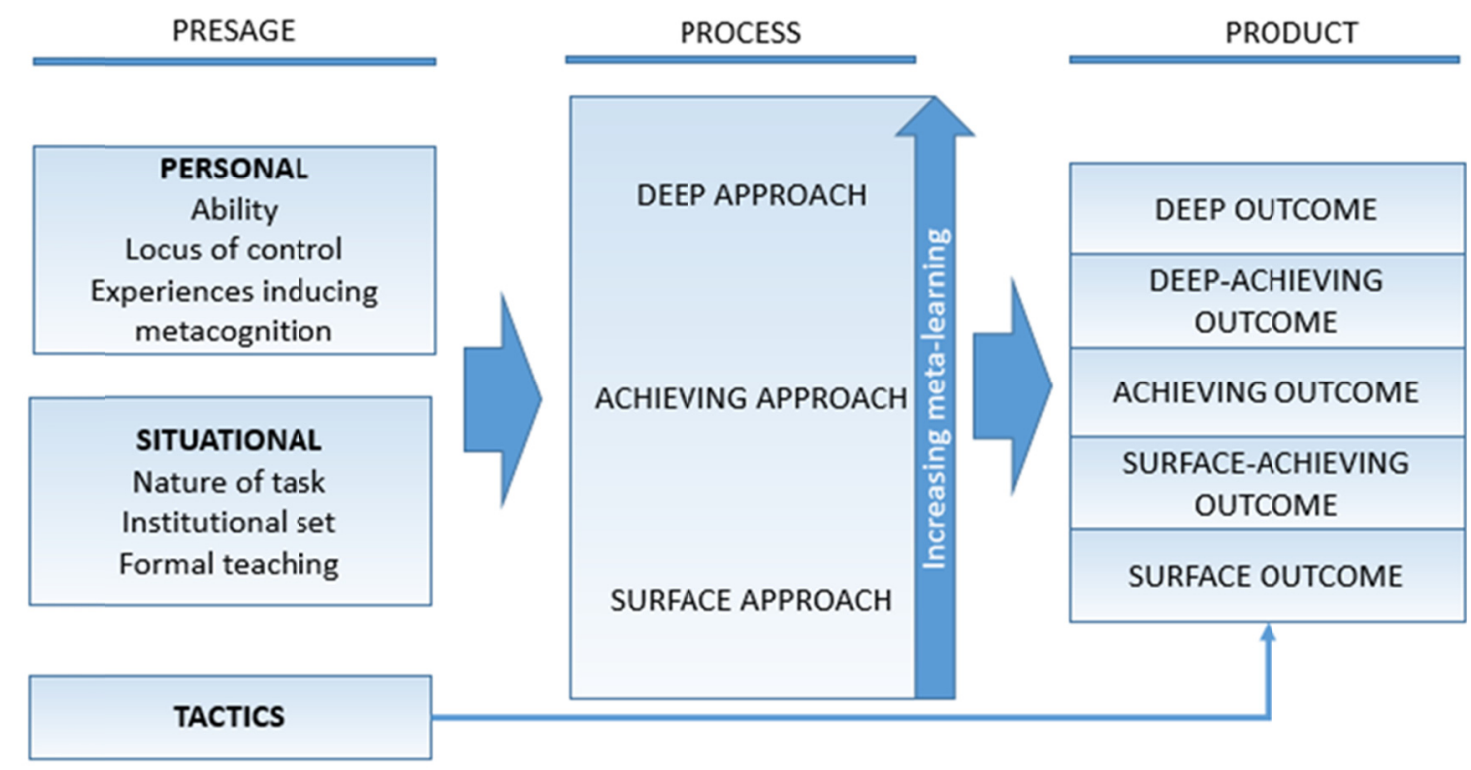

Figure 6. Model used in the original SPQ manual (adapted from Biggs, 1987).

In the last iteration of the original SPQ, the three main scales (deep, achieving, and surface) are described as factors that determine the way a student approaches learning, with the student's approach being a composite of a motive and appropriate strategy (Table 2) (Biggs, 1987). The SPQ in this format was said to operationalize these approaches, with the scale and subscale profiles said to represent an individual's general orientation to learning 
(Biggs, 1987).

In terms of process factors Biggs (1987) highlights four main points:

1) The ways in which students engage in a task relates to surface and deep strategies, while achieving strategy describes the students organizational skills used during a task in temporal and spatial contexts. Thus composite approaches are possible (e.g. Deep achieving, surface achieving approaches).

2) The three different approaches produce different learning outcomes. The most desirable in formal education being the composite deep-achieving approach.

3) The approaches “... describe fairly consistent orientations, or learning styles, displayed by students" (p.4), but can be "strongly influenced by immediate situational factors." (p.4).

4) Learning approach is most effective if students are consciously aware of their own learning processes and are able to control them. This meta-learning process is based on the idea that students adopt strategies that are congruent with their motives.

\section{The Integration of Meta-Learning Concepts}

The focus on the meta-learning concept in relation to the P3 model and the SPQ were first investigated in depth in Biggs (1985), where it was recognised that effective learning under institutional conditions requires that students understand task demands and that they are aware of their intentions of how to meet those demands. Additionally, it was recognised that effective learning by a student requires that they realistically assess their cognitive resources and exert control over these resources (Biggs, 1985). In this same study, Biggs establishes the notion that deep, achieving, and surface approaches involve varying degrees of meta-learning that lead to different learning outcomes (Biggs, 1985). This relationship is clearly illustrated in Biggs (1987) model (see Figure 6).

Importantly, Biggs makes it clear that approaches to learning are not necessarily limited to three major approaches (deep, achieving, and surface), but provide a wide currency in the literature on student learning (Biggs, 1985). As an example, Taylor (1984) suggests four distinct forms of approaches (or orientations), which include four distinct types, namely, academic, vocational, personal, and social. Essentially Taylor (1984) argues that "study patterns are a result of a complex negotiation between their orientation and their perception of the situational context within which they must work." (p. iii). However, even though other orientations clearly exist, in the context of Biggs' prior research and modelling, metacognition is investigated in context of what Biggs considers to be the most important approaches (deep, achieving, and surface).

Understanding the meaning behind the meta-learning terminology used in Biggs (1987) the SPQ is very clear when referring to the explanation in Biggs (1985), where it is stated that meta-learning “... refers specifically to learning and study processes in institutional settings, and more particularly to students' awareness of their motives, and control over their strategy selection and deployment." (p.192). Furthermore, it was also suggested that while meta-learning is most likely to be involved with deep and achieving approach, it also may occur in using surface approach in cases where students are required to learn fact and detail. However, it is made clear that surface approach is usually associated with an inappropriately deployed strategy, rather than a result of a metacognitive decision (Biggs, 1985). This supports the position taken by Biggs (1987), where the "general model of student learning" (p. 6) indicates that the higher the level of meta-learning the deeper the approach.

The tactics referred to in the illustration of "general model of student learning" in Biggs (1987), but not elaborated on, also take their origins from the improved model developed in Biggs (1985). Biggs (1985) indicates that a long-standing issue in literature related to student learning is the extent to which students can be assisted (trained) to be better learners. The model presented possesses the question whether the ability of students to be trained is dependent on a student's meta-learning ability. Furthermore, Biggs (1985) states that if "self-awareness cannot be induced, for whatever reason, then it seems that one is left with teaching highly specific tactics that are close to the task, and "do the trick" without necessarily any metacognitive insight on the part of the student." (p. 205); this explains the apparent relationship between tactics and surface approach as depicted by Biggs (1987).

In terms of meta-learning, Biggs (1987) describes two kinds of awareness regarding a student's control over their own learning:

1) Awareness about what the learning task is about and that they are doing the act of learning in a certain way.

2) Awareness of one's motives or intentions, the task requirements, and an understanding of whether one can meet the requirements. 
Table 2. Iteration of the SPQ that used three main scales (deep, achieving, and surface) (adapted from Biggs, 1987)

\begin{tabular}{|c|c|c|}
\hline Approach & Motive & Strategy \\
\hline $\begin{array}{l}\text { Surface } \\
\text { (The way the student is engaged in the task). } \\
\text { Student uses retention of factual detail at the } \\
\text { expense of structural relationships. Student may } \\
\text { feel dissatisfaction, boredom or dislike (p.3). }\end{array}$ & $\begin{array}{l}\text { Surface Motive } \\
\text { Student attempts to minimally meet } \\
\text { requirements of study. Balance act } \\
\text { between failure and required workload. }\end{array}$ & $\begin{array}{l}\text { Surface Strategy } \\
\text { Student limits targets to bare essentials, } \\
\text { reproducing them via a rote learning } \\
\text { strategy. }\end{array}$ \\
\hline $\begin{array}{l}\text { Deep } \\
\text { (The way the student is engaged in the task). } \\
\text { Student uses this approach to understand the } \\
\text { structural complexity of the task. } \\
\text { Student has positive feelings (p.4). }\end{array}$ & $\begin{array}{l}\text { Deep Motive } \\
\text { Relates to students intrinsic interest. } \\
\text { Student appears interested in developing } \\
\text { competence. }\end{array}$ & $\begin{array}{l}\text { Deep Strategy } \\
\text { Student reads widely and discovers meaning } \\
\text { by inter-relating previous knowledge. }\end{array}$ \\
\hline $\begin{array}{l}\text { Achieving } \\
\text { (The way the student organises temporal and } \\
\text { spatial contexts). }\end{array}$ & $\begin{array}{l}\text { Achieving Motive } \\
\text { Student aims to achieve higher grades, } \\
\text { whether or not they find the material } \\
\text { interesting. }\end{array}$ & $\begin{array}{l}\text { Achieving Strategy } \\
\text { A student organises their time and } \\
\text { workspace. Works to schedule, reads } \\
\text { suggested readings and behaves like a model } \\
\text { student. }\end{array}$ \\
\hline
\end{tabular}

\section{The Traditional Theoretical Basis of the SPQ}

A key distinction in study behaviour inventories has been the contrast between two general perspectives, one referred to as information processing theory, often considered as being at the heart of cognitive psychology and referred to as the information processing (IP) approach (e.g., Biggs, 1993b); and the other perspective, student approaches to learning (SAL), which Biggs et al. (2001) indicates is more appropriate in context-dependent student learning where a student's strategy are dependent on a variety of factors. This is in contrast to information processing theories which aim to address universal mechanisms (Biggs et al., 2001).

The departure from the IP approach, which as an example was used in the development of the SBQ (Biggs et al., 2001) to SAL models are usually characterized as being derived from two major directions, firstly, in-depth qualitative interviews with students about how students perceived a task and how they went about learning it (e.g. Marton and Saljo, 1976), and secondly, quantitative methods (Biggs, 1993b). Regardless of the direction of SAL sub-theories, they are all based on “...the notion that students' perceptions and learning-related activities are central to teaching and learning..." (p. 134).

\section{The Revise Study Process Questionnaire (R-SPQ-2F)}

At the heart of the P3 model is the process level, which Biggs et al. (2001) describes as being at the heart of the teaching and learning system. It is at this process level where the learning related activity either does or does not produce the desired outcome (Biggs et al., 2001). Biggs et al. (2001) indicate that the teacher's job is to help students to engage in the learning process. However, it is made clear that what the student does is more important than what the teacher does. Additionally, it is made clear that the teacher's job is to encourage students to avoid the use of a surface approach to learning and instead adopt a deeper approach (Shuell, 1986; Biggs et al., 2001). Given this perspective, viewing mean scores obtained from the revised SPQ as an index of the quality of teaching (Biggs et al., 2001) gives the researcher a strategy to assess whether the activity helps to produce the desired outcome. Essentially, the approach a student takes is dependent on the relationship between student, context, and task, with both the teacher and student being jointly responsible for the outcome (Biggs et al., 2001).

\section{What the SPQ Measures}

Biggs et al. (2001) describes the SPQ and the scores obtained as a generic way of describing a student's ongoing approaches in terms of the process component of the P3 model. As an example, if a student finds a particular approach will not work under certain conditions, the student may decide to take either a desirable approach (deep) or a less desirable approach (surface) (Biggs et al., 2001). In this context an SPQ score gives an indication of how specific tasks have been handled. Additionally, Biggs et al. (2001) also describes two other levels of the P3 model to which possible interactions can take place (presage and product level). Firstly, the presage level, which describes the difference between students under a particular teaching context (preferred approach), and second, the product level, which describes how teaching contexts differ (contextual approach). In summary, Biggs et al. 
(2001) indicates that SPQ scores are quality indicators at all three levels of the P3 model (presage, process, and product).

\section{Conclusion}

Baeten, Kyndt, Struyven, and Dochy (2010) describe the "approaches to learning" terminology as a means to describe students' approaches to learning tasks, stating that, "over the past decades, a large amount of research has been conducted on students' learning in higher education" (p. 244). More specifically, the Revised Study Process Questionnaire, a commonly used tool to measure approaches to learning, continues to be applied in a wide range of research (Vaughan, 2016). Given this fact, the importance of providing summaries of the conceptual background of the tools development could be very useful for researchers looking to use this tool. We have provided a compact but comprehensive review of the conceptual basis for the development of the original SPQ and later the revised version in an easy to digest format that could potentially save future researchers interested in using the R-SPQ-2F a lot of time.

\section{References}

Ahmann, J. S., \& Clock, M. D. (1957). The utility of study habits and attitudes inventory in a college reading program. The Journal of Educational Research, 51(4), 297-303. https://doi.org/10.1080/00220671.1957.10882470

Baeten, M., Kyndt, E., Struyven, K., \& Dochy, F. (2010). Using student-centred learning environments to stimulate deep approaches to learning: Factors encouraging or discouraging their effectiveness. Educational Research Review, 5, 243-260. https://doi.org/10.1016/j.edurev.2010.06.001

Biggs, J. (1993a). What do inventories of students' learning processes really measure? A theoretical review and clarification. British Journal of Educational Psychology, 63(1), 3-19. https://doi.org/10.1111/j.2044-8279.1993.tb01038.x

Biggs, J. B. (1970). Faculty patterns in study behaviour. Australian Journal of Psychology, 22(2), 161-174. https://doi.org/10.1080/00049537008254570

Biggs, J. B. (1976). Dimensions of study behaviour: another look at the ATI. British Journal of Educational Psychology, 46, 68-80. https://doi.org/10.1111/j.2044-8279.1976.tb02987.x

Biggs, J. B. (1978), individual and group differences in study processes. British Journal of Educational Psychology, 48, 266-279. https://doi.org/10.1111/j.2044-8279.1978.tb03013.x

Biggs, J. B. (1979). Individual differences in study processes and the quality of learning outcomes. Higher education, 8(4), 381-394. https://doi.org/10.1007/BF01680526

Biggs, J. B. (1985). The role of metalearning in study processes. British Journal of Educational Psychology, 55(3), 185-212. https://doi.org/10.1111/j.2044-8279.1985.tb02625.x

Biggs, J. B. (1987). The Study Process Questionnaire (SPQ): Manual. Hawthorn, Vic.: Australian Council for Educational Research.

Biggs, J. B. (1993b). From theory to practice: A cognitive systems approach. Higher Education Research and Development, 12(1), 73-85. https://doi.org/10.1080/0729436930120107

Biggs, J. B., \& Das, J. P. (1973). Extreme Response Set, Internality-Externality and Performance. British Journal of Social and Clinical Psychology, 12(2), 199-210. https://doi.org/10.1111/j.2044-8260.1973.tb00867.x

Biggs, J., Kember, D., \& Leung, D. Y. (2001). The revised two-factor study process questionnaire: R-SPQ-2F. British Journal of Educational Psychology, 71(1), 133-149. https://doi.org/10.1348/000709901158433

Brown, W. F., \& Holtzman, W. H. (1955). A study-attitudes questionnaire for predicting academic success. Journal of Educational Psychology, 46(2), 75. https://doi.org/10.1037/h0039970

Carter, H. D. (1948). Methods of learning as factors in the prediction of school success. The Journal of Psychology, 26(1), 249-258. https://doi.org/10.1080/00223980.1948.9917407

Cooper, B., \& Foy, J. M. (1969). Students' study habits, attitudes and academic attainment. Higher Education Quarterly, 23(2), 203-212. https://doi.org/10.1111/j.1468-2273.1969.tb01143.x

Dunkin, M. J., \& Biddle, B. J. (1974). The Study of Teaching. New York: Holt, Rinehart \& Winston.

Entwistle, N. J., \& Brennan, T. (1971). The academic performance of students. British Journal of Educational Psychology, 41(3), 268-276. https://doi.org/10.1111/j.2044-8279.1971.tb00671.x 
Entwistle, N. J., \& Wilson, J. D. (1977). Degrees of excellence: the academic achievement game. London; Toronto: Hodder and Stoughton.

Entwistle, N. J., Nisbet, J., Entwistle, D., \& Cowell, M. D. (1971). Academic performance of students. 1. Prediction from scales of motivation and study methods. British Journal of Educational Psychology, 41(n), 258.

Gibbons, K. C., \& Savage, R. D. (1965). Intelligence, study habits and personality factors in academic success. Durham Research Review, 5, 8-12.

Lafitte, P. (1963). The student's personality and work. Department of Psychology, University of Melbourne.

Marton, F., \& Säljö, R. (1976). On qualitative differences in learning: I-Outcome and process. British Journal of Educational Psychology, 46(1), 4-11. https://doi.org/10.1111/j.2044-8279.1976.tb02980.x

Shatin, L. (1967). Study skills in medical education: a report and analysis. Journal of Medical Education, 42, 833-840. https://doi.org/10.1097/00001888-196709000-00004

Sherman, T. (1991). Book Review: Study-Habits Inventory. Journal of Psychoeducational Assessment, 9(1), 89-90. https://doi.org/10.1177/073428299100900111

Shuell, T. J. (1986). Cognitive conceptions of learning. Review of Educational Research, 56(4), 411-436. https://doi.org/10.3102/00346543056004411

Stes, A., De Maeyer, S., \& Van Petegem, P. (2013). Examining the cross-cultural sensitivity of the Revised Two-factor Study Process Questionnaire (R-SPQ-2F) and validation of a Dutch version. PloS one, 8(1), e54099. https://doi.org/10.1371/journal.pone.0054099

Taylor, E. M. (1983). Orientation to Study: A Longitudinal Investigation of Two Degree Courses in One University (Doctoral thesis, University of Surrey).

Vaughan, B. (2016). Confirmatory factor analysis of the Study Process Questionnaire in an Australian osteopathy student population. International Journal of Osteopathic Medicine, 20, 62-67. https://doi.org/10.1016/j.ijosm.2016.03.001

Watkins, D., \& Hattie, J. (1992). The motive-strategy congruence model revisited. Contemporary Educational Psychology, 17(2), 194-198. https://doi.org/10.1016/0361-476X(92)90058-7

Watkins, D., \& Hattie, J. (1992). The motive-strategy congruence model revisited. Contemporary Educational Psychology, 17(2), 194-198. https://doi.org/10.1016/0361-476X(92)90058-7

Wilson, J. D. (1977). Degrees of excellence: the academic achievement game. London; Toronto: Hodder and Stoughton.

Wrenn, C. G. (1941). Study-Habits Inventory (Revised Edition). Stanford University Press.

\section{Copyrights}

Copyright for this article is retained by the author(s), with first publication rights granted to the journal.

This is an open-access article distributed under the terms and conditions of the Creative Commons Attribution license (http://creativecommons.org/licenses/by/4.0/). 